\title{
Nicotine impact on melanogenesis and antioxidant defense system in HEMn-DP melanocytes
}

\author{
Marcin Delijewski • Dorota Wrześniok • \\ Michał Otręba · Artur Beberok · Jakub Rok • \\ Ewa Buszman
}

Received: 23 January 2014 / Accepted: 2 June 2014/Published online: 19 June 2014

(c) The Author(s) 2014. This article is published with open access at Springerlink.com

\begin{abstract}
Nicotine is a compound of tobacco plants and is responsible for addictive properties of tobacco which is used by about one billion of smokers all over the world. Recently, nicotine has drawn even more attention due to its presumed neuroprotective and antioxidant features as far as common use in various forms of smoking cessation therapies. It is suggested that nicotine may be accumulated in human tissues containing melanin. This may in turn influence biochemical processes in human cells producing melanin. The aim of this study was to examine the impact of nicotine on melanogenesis and antioxidant defense system in cultured normal human melanocytes (HEMnDP). Nicotine induced concentration-dependent loss in melanocytes viability. The value of $\mathrm{EC}_{50}$ was determined to be $2.52 \mathrm{mM}$. Nicotine modulated melanin biosynthesis in normal human melanocytes. Significant changes in hydrogen peroxide content and cellular antioxidant enzymes: SOD, CAT, and GPx activities were stated in melanocytes exposed to nicotine, which indicates alterations of antioxidant defense system. The results obtained in vitro may explain a potential influence of nicotine on biochemical processes in melanocytes in vivo during longterm exposition to nicotine.
\end{abstract}

Keywords Nicotine - Melanocytes - Melanogenesis · Tyrosinase $\cdot$ Antioxidant enzymes

M. Delijewski · D. Wrześniok · M. Otręba · A. Beberok ·

J. Rok · E. Buszman $(\bowtie)$

Department of Pharmaceutical Chemistry, Faculty of Pharmacy,

Medical University of Silesia, Jagiellońska 4, 41-200 Sosnowiec, Poland

e-mail: ebuszman@sum.edu.pl

\section{Introduction}

Nicotine being a main compound of tobacco plants (Nicotiana) is responsible for tobacco addiction that leads to high occurrence of smoking-related premature deaths reaching even a number of 435,000 diseases each year in the United States, mainly due to cancer, cardiovascular and pulmonary diseases induced by toxins in tobacco smoke [1]. On the other hand, nicotine is a commonly used agent for smoking cessation therapies and promising substance in pharmacological attempts because of its presumed neuroprotective and antioxidant properties [2-4].

Nicotine can be absorbed from cigarette smoke through lungs, from chewing tobacco through oral mucosa, or from nicotine replacement therapy (NRT) that consists of nicotine gums, inhalers, nasal sprays, sublingual tablets, lozenges, and from transdermal patches through skin. After reaching brain, it causes a reinforcement effect, which rapidity depends on speed, quantity, and form of absorption. The fastest and the most effective delivery of nicotine is the tobacco smoke, as it gives a potentiality of adjusting the individual level of nicotine that reaches brain, by maintaining speed, frequency, and depth of puffs by each cigarette. Differently from tobacco smoke, that delivers nicotine directly to the lungs, bioavailability of nicotine through mucosa of the oral cavity is about $50-80 \%$. In case of transdermal delivery, nicotine appears in bloodstream after the initial lag time of about $1 \mathrm{~h}[5,6]$. Tobacco smoke is thereby the most effective way of nicotine absorption which is, however, abundant in accompanied cancerogenic compounds. Taking into account the effectiveness and safety of NRT, one can consider the contribution of melanin in the distribution of nicotine in body tissues.

Melanin is a natural polymeric pigment produced in the interior of melanocytes, in specialized membrane-bound 
organelles, melanosomes. It occurs in the skin, as well as in other organs and structures such as the eye, hair, inner ear, heart, lungs, liver, lymphocytes, and brain. Melanin is synthesized in multistep process called menalogenesis in which three main melanogenic metalloenzymes are involved: tyrosinase, tyrosinase-related protein 1 (TRP1), and tyrosinase-related protein 2 (TRP2). The most critical enzyme for the whole process is tyrosinase [7, 8]. Melanin is traditionally believed to work as UV radiation absorbent as well as antioxidant agent and free radicals scavenger [9]. Being a diversified polymer containing various reactive centres, melanin is capable of binding a number of chemicals and medicinal substances, including aminoglycoside antibiotics [10], fluoroquinolones [11], anticancer agents [12], and psychotropic drugs [13].

The literature suggests that nicotine may be accumulated in human tissues containing melanin and retention in these tissues may increase melanin synthesis. This may in turn influence nicotine metabolism, level of nicotine addiction, and good results of smoking cessation therapies [14]. Considering this fact it can be assumed that the presence of nicotine could lead to melanin pigmentations, which were observed in oral mucosa of smokers and even children exposed to second hand cigarette smoke [15-17].

The major findings from previous research on nicotine's affinity to melanin include proofs for formation of nicotine adducts to melanin's intermediate, dopaquinone, during in vitro synthesis of melanin in presence of nicotine [18], tight association of nicotine to melanin $[19,20]$, high incorporation of nicotine to the pigmented hair during hair formation [21], and accumulation and long-term retention of nicotine in melanin-containing tissues in mice [22]. However, until now there were no exact studies on the effect of nicotine on human cells, focusing on biochemical processes involving biosynthesis of melanin and antioxidant status in cell culture. Interactions between nicotine and melanin may be of particular importance in case of dark-pigmented individuals that have more melanin and may sequester nicotine in the body. This accumulation of nicotine may be associated with reduction of nicotine clearance, and increase in time one is exposed to nicotine and higher dependence that may result in lower tobacco cessation rates [23].

Previously, we documented that fluoroquinolones: ciprofloxacin [11] and lomefloxacin [24], as well as aminoglycoside antibiotics: amikacin [25], kanamycin [26], netilmicin [27], and streptomycin [28] suppressed melanin biosynthesis in human light pigmented melanocytes. Our studies also demonstrated that the analyzed drugs affected antioxidant enzymes activities in HEMa-LP melanocytes.

In order to estimate the nicotine-melanin relationship in living cells, we examined the effect of nicotine on viability, melanogenesis and antioxidant status in cultured normal human melanocytes (HEMn-DP).

\section{Materials and methods}

Nicotine, phosphated-buffered saline (PBS), 3,4-dihydroxyL-phenylalanine (L-DOPA), and amphotericin B were purchased from Sigma-Aldrich Inc. (USA). Neomycin sulfate was obtained from Amara (Poland). Penicillin was acquired from Polfa Tarchomin (Poland). Growth medium M-254 and human melanocyte growth supplement-2 (HMGS-2) were obtained from Cascade Biologics (UK). Trypsin/EDTA was obtained from Cytogen (Poland). Cell Proliferation Reagent WST-1 was purchased from Roche GmbH (Germany). The remaining chemicals were produced by $\mathrm{POCH}$ S.A. (Poland).

\section{Cell culture}

The normal human epidermal melanocytes (HEMn-DP, Cascade Biologics) were grown according to the manufacturer's instruction. The cells were cultured in M-254 basal medium supplemented with HMGS-2, penicillin $(100 \mathrm{U} / \mathrm{ml})$, neomycin $(10 \mu \mathrm{g} / \mathrm{ml})$, and amphotericin B $(0.25 \mu \mathrm{g} / \mathrm{ml})$ at $37^{\circ} \mathrm{C}$ in $5 \% \mathrm{CO}_{2}$. All experiments were performed using cells in the passages 5-8.

Cell viability assay

The viability of melanocytes was evaluated by the WST-1 (4-[3-(4-iodophenyl)-2-(4-nitrophenyl)-2H-5-tetrazolio]-1,3benzene disulphonate) colorimetric assay. WST-1 is a watersoluble tetrazolium salt, the rate of WST-1 cleavage by mitochondrial dehydrogenases correlates with the number of viable cells. In brief, 5,000 cells per well were placed in a 96-well microplate in a supplemented M-254 growth medium and incubated at $37{ }^{\circ} \mathrm{C}$ and $5 \% \mathrm{CO}_{2}$ for $48 \mathrm{~h}$. Then, the medium was removed and cells were treated with nicotine solutions in a concentration range from 0.0001 to $10 \mathrm{mM}$. After 21-h incubation, $10 \mu \mathrm{l}$ of WST- 1 was added to $100 \mu \mathrm{l}$ of culture medium in each well, and the incubation was continued for three hours. The absorbance of the samples was measured at $440 \mathrm{~nm}$ with a reference wavelength of $650 \mathrm{~nm}$, against the controls (the same cells but not treated with nicotine) using a microplate reader UVM 340 (Biogenet, Poland). The controls were normalized to $100 \%$ for each assay and treatments were expressed as the percentage of the controls.

Measurement of melanin content

The melanocytes were seeded in T-25 flasks at a density of $1 \times 10^{5}$ cells per flask. Nicotine treatment in a concentration range from 0.0001 to $1.0 \mathrm{mM}$ began $48 \mathrm{~h}$ after seeding. After $24 \mathrm{~h}$ of incubation, the cells were detached with trypsin/EDTA. Cell pellets were placed into 
Eppendorf tubes, dissolved in $100 \mu \mathrm{l}$ of $1 \mathrm{M} \mathrm{NaOH}$ at $80^{\circ} \mathrm{C}$ for $1 \mathrm{~h}$, and then centrifuged for $20 \mathrm{~min}$ at $16,000 \mathrm{~g}$. The supernatants were placed into a 96-well microplate and absorbance was measured at $405 \mathrm{~nm}-\mathrm{a}$ wavelength at which melanin absorbs light [29]. Melanin content in nicotine-treated cells was expressed as the percentage of the controls (untreated melanocytes).

\section{Tyrosinase activity assay}

Tyrosinase activity in HEMn-DP cells was determined by measuring the rate of oxidation of L-DOPA to DOPAchrome, according to the method described by Kim et al. [30] and Busca et al. [31], with a slight modification. The cells were cultured at a density of $1 \times 10^{5}$ cells in T-25 flasks for $48 \mathrm{~h}$. After 24-h incubation with nicotine (concentration range from 0.0001 to $1.0 \mathrm{mM}$ ), cells were lysed and clarified by centrifugation at $10,000 \mathrm{~g}$ for $5 \mathrm{~min}$. A tyrosinase substrate L-DOPA $(2 \mathrm{mg} / \mathrm{ml})$ was prepared in the same lysis phosphate buffer. $100 \mu$ of each lysate was put in a 96-well plate, and the enzymatic assay was initiated by the addition of $40 \mu \mathrm{l}$ of L-DOPA solution at $37^{\circ} \mathrm{C}$. Absorbance was measured every $10 \mathrm{~min}$ for at least $1.5 \mathrm{~h}$ at $475 \mathrm{~nm}$ using a microplate reader. Tyrosinase activity was expressed as the percentage of the controls (untreated melanocytes).

\section{Superoxide dismutase (SOD) assay}

Superoxide dismutase (SOD) activity was measured using an assay kit (Cayman, MI, USA) according to the manufacturer's instruction. This kit utilizes a tetrazolium salt for the detection of superoxide radicals generated by xanthine oxidase and hypoxanthine. One unit of SOD was defined as the amount of enzyme needed to produce $50 \%$ dismutation of superoxide radical. SOD activity was expressed in U/mg protein. The samples were taken from the same lysates that were used for tyrosinase activity assay.

Catalase (CAT) assay

Catalase (CAT) activity was measured using an assay kit (Cayman, MI, USA) according to the manufacturer's instruction. This kit utilizes the peroxidatic function of CAT for determination of enzyme activity. The method is based on the reaction of the enzyme with methanol in the presence of an optimal concentration of $\mathrm{H}_{2} \mathrm{O}_{2}$. The formaldehyde produced is measured colorimetrically with 4-amino-3-hydrazino-5-mercapto-1,2,4-triazole (Purpald) as the chromogen. One unit of CAT was defined as the amount of enzyme that causes the formation of $1.0 \mathrm{nmol}$ of formaldehyde per minute at $25^{\circ} \mathrm{C}$. CAT activity was expressed in $\mathrm{nmol} / \mathrm{min} / \mathrm{mg}$ protein. The samples were taken from the same lysates that were used for tyrosinase activity assay.

Glutathione peroxidase (GPx) assay

Glutathione peroxidase (GPx) activity was measured using an assay kit (Cayman, MI, USA) according to the manufacturer's instruction. The measurement of GPx activity is based on the principle of a coupled reaction with glutathione reductase (GR). The oxidized glutathione (GSSG) formed after reduction of hydroperoxide by GPx is recycled to its reduced state by GR in the presence of NADPH. The oxidation of NADPH is accompanied by a decrease in absorbance at $340 \mathrm{~nm}$. One unit of GPx was defined as the amount of enzyme that catalyzes the oxidation of $1 \mathrm{nmol}$ of NADPH per minute at $25^{\circ} \mathrm{C}$. GPx activity was expressed in $\mathrm{nmol} / \mathrm{min} / \mathrm{mg}$ protein. The samples were taken from the same lysates that were used for tyrosinase activity assay.

Hydrogen peroxide $\left(\mathrm{H}_{2} \mathrm{O}_{2}\right)$ assay

Hydrogen peroxide $\left(\mathrm{H}_{2} \mathrm{O}_{2}\right)$ content was measured using an assay kit (Cell Biolabs, Inc., USA) according to the manufacturer's instruction. This method is based on the ability of sorbitol to convert peroxide to a peroxyl radical, which oxidizes $\mathrm{Fe}^{2+}$ into $\mathrm{Fe}^{3+}$. Then $\mathrm{Fe}^{3+}$ reacts with an equimolar amount of xylenol orange in the presence of acid to create a purple product that absorbs light at maximal wavelength $595 \mathrm{~nm}$. The antioxidant-butylated hydroxytoluene (BHT) is provided to prevent further undesirable chain peroxidation. Hydrogen peroxide content in the samples was expressed in $\mu \mathrm{mol} / \mathrm{mg}$ protein. The samples were taken from the same lysates that were used for tyrosinase activity assay.

Statistical analysis

In all experiments, mean values of at least three separate experiments $(n=3)$ performed in triplicate \pm standard error of the mean (S.E.M.) were calculated. The results were analyzed statistically using GraphPad Prism 6.01 Software. A value of $p<0.05$ (*) or $p<0.005$ (**), obtained with a Student's $t$ test by comparing the data with those for control (cells without nicotine), was considered statistically significant.

\section{Results}

The effect of nicotine on cell viability

Melanocytes were treated with nicotine in a range of concentrations from 0.0001 to $10 \mathrm{mM}$ for $24 \mathrm{~h}$ (Fig. 1). 


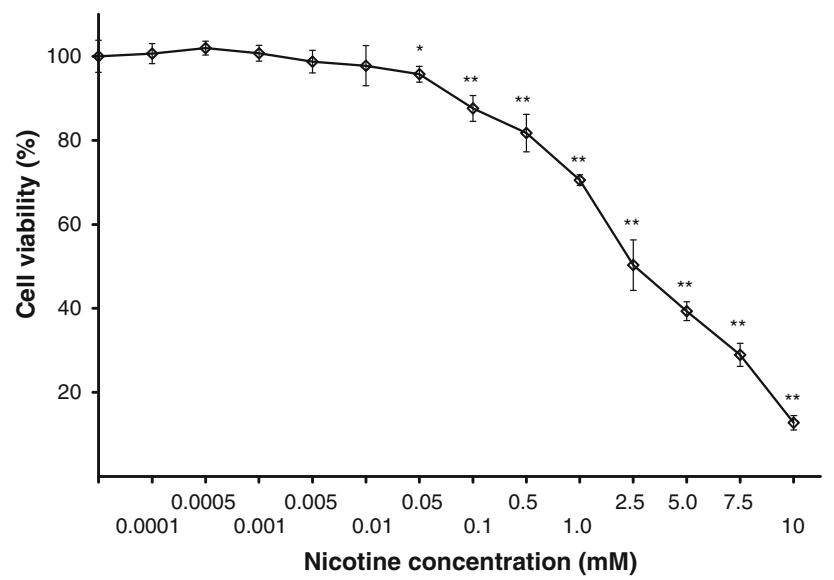

Fig. 1 The effect of nicotine on viability of melanocytes. Cells were treated with various nicotine concentrations $(0.0001-10 \mathrm{mM})$ and examined by the WST-1 assay. Data are expressed as \% of cell viability. Mean values \pm S.E.M. from three independent experiments $(n=3)$ performed in triplicate are presented. $* p<0.05$ versus the control samples; $* * p<0.005$ versus the control samples

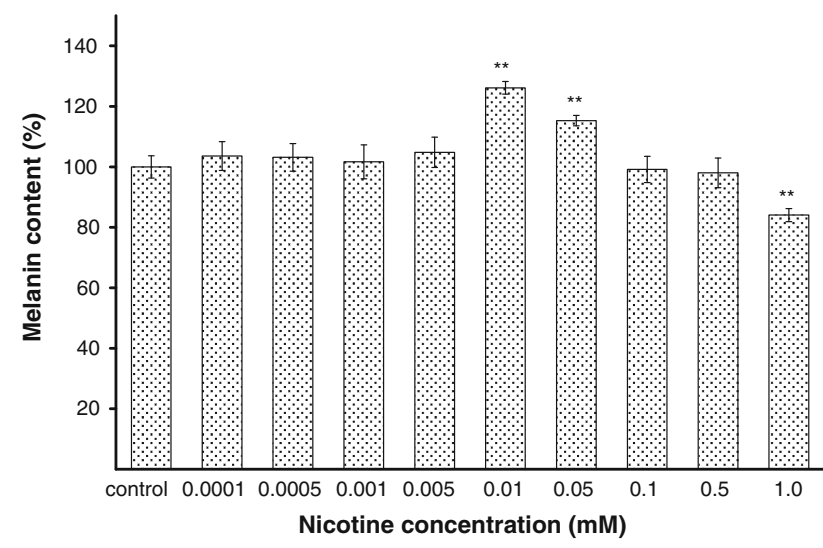

Fig. 2 The effect of nicotine on melanin content in melanocytes. Cells were treated with various nicotine concentrations (0.0001-1.0 mM) for $24 \mathrm{~h}$, and melanin content was measured as described in "Materials and methods" section. Results are expressed as percentages of the controls. Data are mean \pm SEM of at least three independent experiments $(n=3)$ performed in triplicate. $* * p<0.005$ versus the control samples

The cell viability was determined by the WST-1 test assay. At a relative low nicotine concentrations $(0.0001-0.01 \mathrm{mM})$, the loss in cell viability was not statistically significant. Treatment of cells with $0.05,0.1,0.5,1.0,2.5,5.0,7.5$, and $10 \mathrm{mM}$ of nicotine led to the loss of about 4.2, 12.4, 18.3, $29.5,49.7,60.7,71.1$, and $87.2 \%$ in the cell viability, respectively. The value of $\mathrm{EC}_{50}$ (i.e., the concentration of a drug that produces loss in cell viability by $50 \%$ ) was determined to be $2.52 \mathrm{mM}$.

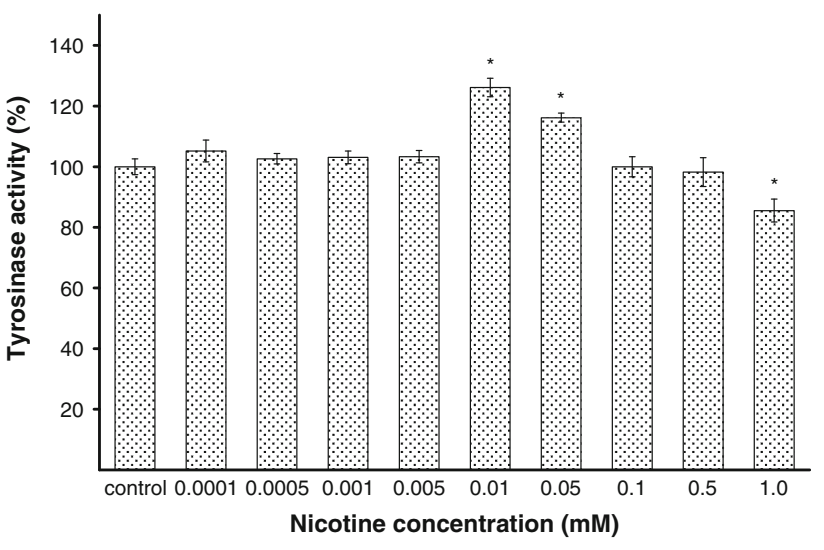

Fig. 3 The effect of nicotine on tyrosinase activity in melanocytes. Cells were treated with various nicotine concentrations (0.0001-1.0 mM) for $24 \mathrm{~h}$, and tyrosinase activity was measured as described in "Materials and methods" section. Data are mean \pm SEM of at least three independent experiments $(n=3)$ performed in triplicate. ${ }^{*} p<0.05$ versus the control samples

The effect of nicotine on melanization process

The effectiveness of melanization process was estimated by measuring the melanin content and cellular tyrosinase activity in melanocytes treated with nicotine in a range of concentrations from 0.0001 to $1.0 \mathrm{mM}$ for $24 \mathrm{~h}$. Nicotine in concentrations from 0.0001 to $0.005 \mathrm{mM}$ and in concentrations of 0.1 and $0.5 \mathrm{mM}$ had no effect on melanin content (Fig. 2). In cells treated with nicotine at concentrations of 0.01 and $0.05 \mathrm{mM}$ for $24 \mathrm{~h}$, melanin production increased by about 26 and $15 \%$, respectively. Treatment of cells with $1.0 \mathrm{mM}$ of nicotine reduced melanin content by about $16 \%$.

Tyrosinase activity in HEMn-DP cells treated with nicotine also changed in a manner correlating well with the effect on melanin formation (Fig. 3). After 24-h incubation with nicotine, tyrosinase activity was suppressed to $86 \%$ at $1.0 \mathrm{mM}$ when compared with the controls. In cells treated with nicotine at concentrations of 0.01 and $0.05 \mathrm{mM}$ for $24 \mathrm{~h}$, tyrosinase activity increased by about 26 and $16 \%$, respectively. Nicotine in the range of concentrations from 0.0001 to $0.005 \mathrm{mM}$ and in concentrations of 0.1 and $0.5 \mathrm{mM}$ had no effect on the cellular tyrosinase activity.

The effect of nicotine on antioxidant enzymes activities

To explain the effect of nicotine on antioxidant status in melanocytes, the activities of SOD, CAT, and GPx were estimated. The $\mathrm{H}_{2} \mathrm{O}_{2}$ content was also measured. Human melanocytes HEMn-DP were exposed to nicotine in concentrations of $0.01,0.05,0.1,0.5$, or $1.0 \mathrm{mM}$ for $24 \mathrm{~h}$. It has 


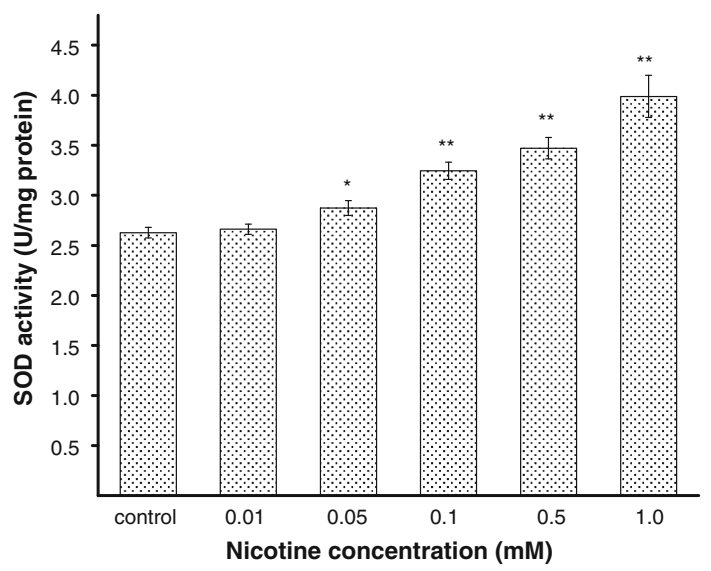

Fig. 4 The SOD activity in HEMn-DP cell after $24 \mathrm{~h}$ incubation with $0.01,0.05,0.1,0.5$, or $1.0 \mathrm{mM}$ of nicotine. Data are mean $\pm \mathrm{SEM}$ of at least three independent experiments $(n=3)$ performed in triplicate. ${ }^{*} p<0.05$ versus the control samples; ${ }^{*} p<0.005$ versus the control samples

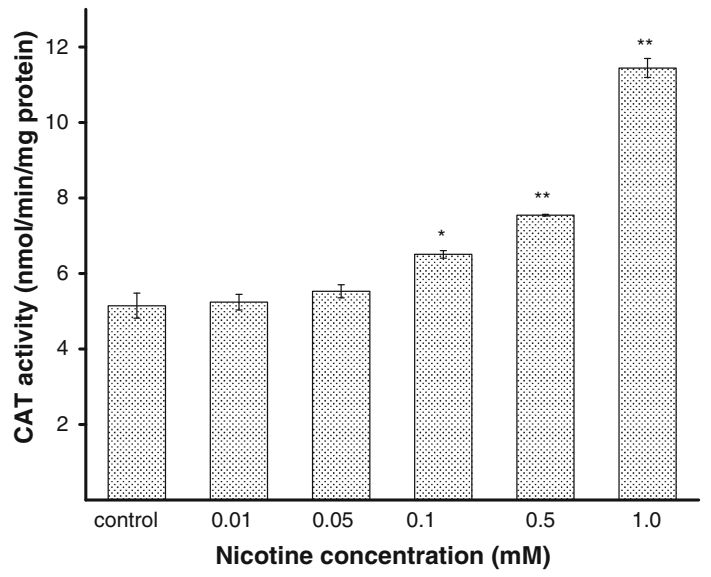

Fig. 5 The CAT activity in HEMn-DP cell after $24 \mathrm{~h}$ incubation with $0.01,0.05,0.1,0.5$, or $1.0 \mathrm{mM}$ of nicotine. Data are mean $\pm \mathrm{SEM}$ of at least three independent experiments $(n=3)$ performed in triplicate. ${ }^{*} p<0.05$ versus the control samples; $* * p<0.005$ versus the control samples

been demonstrated that the activity of SOD, i.e., the enzyme which catalyzes the formation of hydrogen peroxide from superoxide anion, increases with increasing concentration of nicotine (Fig. 4). The treatment of cells with 0.05, 0.1, 0.5 , or $1.0 \mathrm{mM}$ of nicotine, increased the SOD activity by 9 , 24,32 , or $52 \%$, respectively, as compared with the controls. Nicotine in the concentration of $0.01 \mathrm{mM}$ had no effect on the cellular SOD activity. CAT and GPx work together to catalyze the breakdown of hydrogen peroxide, produced by SOD, to water. The intracellular CAT activity was significantly increased by 26 or $47 \%$ for cells treated with nicotine in concentration of 0.1 or $0.5 \mathrm{mM}$,

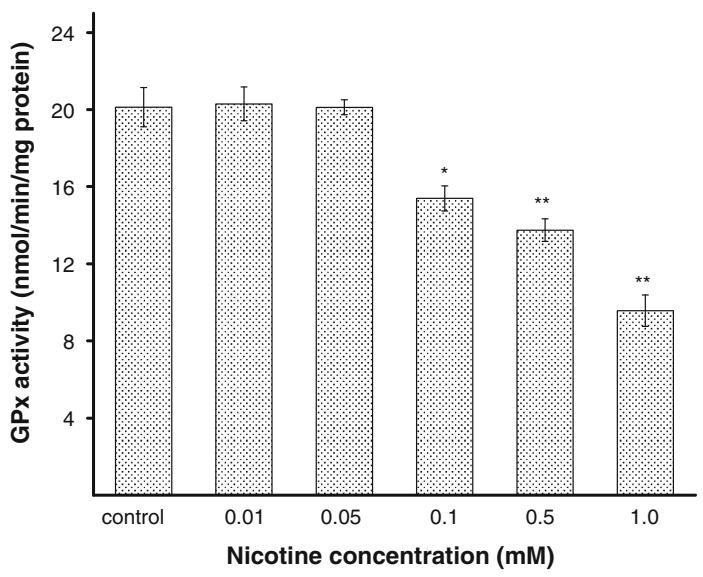

Fig. 6 The GPx activity in HEMn-DP cell after $24 \mathrm{~h}$ incubation with $0.01,0.05,0.1,0.5$, or $1.0 \mathrm{mM}$ of nicotine. Data are mean \pm SEM of at least three independent experiments $(n=3)$ performed in triplicate. ${ }^{*} p<0.05$ versus the control samples; $* * p<0.005$ versus the control samples

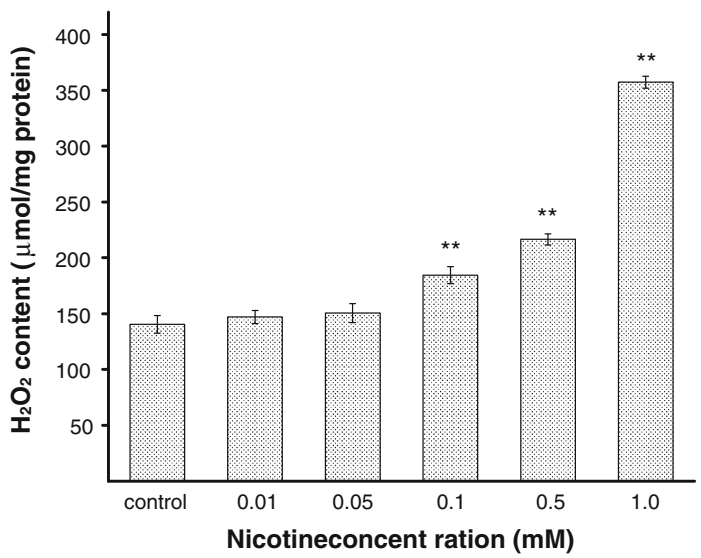

Fig. 7 The hydrogen peroxide $\left(\mathrm{H}_{2} \mathrm{O}_{2}\right)$ content in HEMn-DP cell after $24 \mathrm{~h}$ incubation with $0.01,0.05,0.1,0.5$, or $1.0 \mathrm{mM}$ of nicotine. Data are mean \pm SEM of at least three independent experiments $(n=3)$ performed in triplicate. $* * p<0.005$ versus the control samples

respectively, and it increased more than twofold (to $222 \%$ ) for cells exposed to nicotine in concentration of $1.0 \mathrm{mM}$ (Fig. 5). In contrast to SOD and CAT, the activity of GPx decreased by 24,32 , and $52 \%$ for cells treated with nicotine in concentrations of $0.1,0.5$, and $1.0 \mathrm{mM}$, respectively, in comparison to the control cells (Fig. 6). Nicotine enhanced $\mathrm{H}_{2} \mathrm{O}_{2}$ content in melanocytes (Fig. 7). Treatment of cells with $0.1,0.5$, and $1.0 \mathrm{mM}$ of nicotine increased the $\mathrm{H}_{2} \mathrm{O}_{2}$ content by 31,54 , and $154 \%$, respectively, as compared with the controls. Nicotine in the concentration of 0.01 and $0.05 \mathrm{mM}$ had no effect on $\mathrm{H}_{2} \mathrm{O}_{2}$ content as well as on cellular CAT and GPx activity. 


\section{Discussion}

The ability of melanin to interact with many drugs and other chemical substances has both beneficial and adverse effects on the body. Binding of potentially dangerous compounds to this biopolymer protects cells from exposure to excessive concentrations of harmful substances through previous accumulation and further elimination in non-toxic concentrations. However, a long-term exposition to xenobiotics with high affinity for melanin may lead to degeneration of pigmented cells. It is believed that the process of drug-induced damages of melanin-containing tissues takes place when the detoxifying capacities of melanin are exhausted [8, 32]. Nicotine forms complexes with melanin and the amounts of nicotine bound to melanin increase with rising initial drug concentrations and prolongation of incubation time. These complexes were characterized by two classes of independent binding sites with the association constants $\mathrm{K}_{1}=2.44 \times 10^{4} \mathrm{M}^{-1}$ and $\mathrm{K}_{2}=7.72 \times$ $10^{2} \mathrm{M}^{-1}$. The total number of binding sites was estimated to be $1,748 \mu \mathrm{mol}$ nicotine/mg melanin [33]. It has been demonstrated that the laboratory synthesis of melanin, involving oxidation of tyrosine under the influence of tyrosinase in the presence of ${ }^{3} \mathrm{H}$-nicotine, results in a polymer with incorporated radionuclide [19]. Data from the literature indicate that concentration of nicotine in some organs is related to the pigmentation [14]. Deposition of nicotine in hair containing melanin takes place both during development of hair and after this process [18, 21]. Melanin-containing tissues can store nicotine up to 30 days after a single injection, what was observed in mice [22, 34]. Interactions of nicotine with melanin are still discussed in the context of possible role of the accumulated nicotine in melanin rich tissues, according to nicotine dependence as a topic of health risk significance. That would surely be important, because melanin could act as a non indifferent factor in absorption of nicotine from cigarette smoke and NRT.

In the present study, the effect of nicotine on melanocytes viability, as well as on melanization process and antioxidant defense system in pigmented cells was analyzed. We used the culture of normal human melanocytes HEMn-DP as an in vitro experimental model system. We have found that nicotine in concentrations from 0.0001 to $10 \mathrm{mM}$ decreases the cell viability in a dose-dependent manner (Fig. 1). The value of $\mathrm{EC}_{50}$ was determined to be $2.52 \mathrm{mM}$.

The obtained results show that nicotine affects the melanization process in tested cell line. For concentrations of nicotine 0.01 and $0.05 \mathrm{mM}$, we observed an activation of melanogenesis expressed by increase in melanin content and tyrosinase activity (Figs. 2, 3). The specific increases in the melanin content for the concentration of nicotine
0.01 and $0.05 \mathrm{mM}$ are probably due to induction of tyrosinase activity by nicotine in these concentrations. The multistep process of melanogenesis is strongly influenced by the key enzyme, tyrosinase. In our study, tyrosinase has increased which correlates with the increasing melanin content. Taking into account the possibility of melanin dispersion occurrence in smokers and in people exposed directly to the effects of nicotine, it can be assumed that the existence of skin coloration may be, among other things, related to the dispersion of melanin-filled melanosomes to the dendrites. It has been shown that smokers' melanocytes contain melanosomes found in the third or fourth stage of development, entirely filled with melanin, while among non-smokers, melanosomes in the second stage prevail [16]. Nicotine would also activate melanization of melanocytes in an indirect way. It happens through betaadrenergic effects of epinephrine, which release from the adrenal medulla is augmented while smoking a cigarette. It may cause an increase in the level of cyclic adenosine monophosphate (cAMP), which is an important factor stimulating the biosynthesis of melanin [35]. In humans smoking cigarettes, levels of cAMP in plasma and urine are increased [36]. There might be also a possibility that the high content of melanin can lead to higher absorption of nicotine and lower tobacco cessation rates [14, 23]. A positive correlation between the degree of melanization and the number of cigarettes smoked per day, the level of cotinine - the main metabolite of nicotine in the urine, and test results on the degree of nicotine dependence based on a questionnaire (Fagerström test) was found [23, 37].

For the concentrations from 0.0001 to $0.005 \mathrm{mM}$ as well as for $0.1 \mathrm{mM}$ and $0.5 \mathrm{mM}$, we observed that the melanin content and tyrosinase activity were similar to control. The lack of increase in the melanin content for the concentrations of nicotine 0.1 and $0.5 \mathrm{mM}$ may be caused by emerging induction of oxidative stress by nicotine that presumably affects the function of tyrosinase enzyme. High $\mathrm{H}_{2} \mathrm{O}_{2}$ content stated for these concentrations may also have inhibitory effect on melanogenic enzymes. For the highest tested concentration of nicotine $(1.0 \mathrm{mM})$ inhibition of melanization process, expressed by reduction of tyrosinase activity and melanin content in melanocytes by about 14 and $16 \%$, respectively, was demonstrated. This indicates that an inhibitory effect of nicotine in concentration of $1.0 \mathrm{mM}$ on melanogenesis is probably due to its direct inhibition of tyrosinase activity.

In the present study, it has been observed for the first time that nicotine causes significant alterations in the activities of antioxidant enzymes: SOD, CAT, and GPx in melanocytes. The concentration-dependent increase in SOD activity, after exposure of melanocytes to nicotine in concentrations from 0.1 to $1.0 \mathrm{mM}$ (Fig. 4), is probably associated with overproduction of the superoxide anion and subsequent 
formation of $\mathrm{H}_{2} \mathrm{O}_{2}$ (Fig. 7), which leads to the increase in CAT activity (Fig. 5). We observed decreased activities of GPx for these nicotine concentrations (Fig. 6), what may be explained by the redundant $\mathrm{H}_{2} \mathrm{O}_{2}$ level that cannot be eliminated. After treatment of cells with nicotine in lower concentrations $(0.01$ and $0.05 \mathrm{mM})$, the activities of antioxidant enzymes, as well as the $\mathrm{H}_{2} \mathrm{O}_{2}$ content were similar to the controls. Increase of oxidative stress in melanocytes can be observed after exposition to nicotine in concentrations higher than $0.1 \mathrm{mM}$. The overproduction of ROS may cause damages in basic cellular components of cells resulting in dysfunctions or leading to cell death [38]. Harmful effects of oxidative stress should be overcome by three main enzymes: SOD, CAT, and GPx. Additionally, the scavenger properties of melanin may complement the effectiveness of the antioxidant system of melanocytes. CAT is the main enzyme responsible for degradation of hydrogen peroxide in melanocytes [39]. Thus, it may be possible that CAT and melanin act synergistically to protect cells from oxidative stress, while lower activity of GPx.

To summarize, we have demonstrated that nicotine at lower concentrations induces melanogenesis in normal human melanocytes, having no influence on cellular antioxidant status. At higher nicotine concentrations (above $0.1 \mathrm{mM}$ ), the occurence of oxidative stress inside melanocytes (expressed by significant changes of antioxidant enzymes activity) was stated.

\section{Conclusion}

The results presented in this work concerning the effect of nicotine on biochemical processes in normal human melanocytes have to be taken into consideration in the assessment of efficacy and safety of NRT, especially in people with high melanin content.

Acknowledgments This work was supported by the Medical University of Silesia (Grant No.KNW-1-094/K/3/0).

Conflict of interest The authors declare that there are no conflicts of interest.

Open Access This article is distributed under the terms of the Creative Commons Attribution License which permits any use, distribution, and reproduction in any medium, provided the original author(s) and the source are credited.

\section{References}

1. Benowitz NL (2010) Nicotine addiction. N Engl J Med 362:2295-2303

2. Takeuchi H, Yanagida T, Inden M, Takata K, Kitamura Y, Yamakawa K, Sawada H, Izumi Y, Yamamoto N, Kihara T,
Uemura K, Inoue H, Taniguchi T, Akaike A, Takahashi R, Shimohama S (2009) Nicotinic receptor stimulation protects nigral dopaminergic neurons in rotenone-induced Parkinson's disease models. J Neurosci Res 87:576-585

3. Williams E, Linert W (2004) In vitro evidence supporting the therapeutic role of nicotine against neurodegeneration. In Vivo 18:391-399

4. Linert W, Bridge MH, Huber M, Bjugstad KB, Grossman S, Arendash GW (1999) In vitro and in vivo studies investigating possible antioxidant actions of nicotine: relevance to Parkinson's and Alzheimer's diseases. Biochim Biophys Acta 1454:143-152

5. Benowitz NL, Hukkanen J, Jacob P 3rd (2009) Nicotine chemistry, metabolism, kinetics and biomarkers. Handb Exp Pharmacol 192:29-60

6. Fant RV, Henningfield JE, Shiffman S, Strahs KR, Reitberg DP (2000) A pharmacokinetic crossover study to compare the absorption characteristics of three transdermal nicotine patches. Pharmacol Biochem Behav 67:479-482

7. Sulaimon SS, Kitchell BE (2003) The biology of melanocytes. Vet Dermatol 14:57-65

8. Larsson BS (1993) Interactions between chemicals and melanin. Pigment Cell Res 6:127-133

9. Brenner M, Hearing VJ (2008) The protective role of melanin against UV damage in human skin. Photochem Photobiol 84:539-549

10. Buszman E, Wrześniok D, Trzcionka J (2007) Interaction of neomycin, tobramycin and amikacin with melanin in vitro in relation to aminoglycosides-induced ototoxicity. Pharmazie 62:210-215

11. Beberok A, Buszman E, Wrześniok D, Otręba M, Trzcionka J (2011) Interaction between ciprofloxacin and melanin: the effect on proliferation and melanization in melanocytes. Eur J Pharmacol 669:32-37

12. Surażynski A, Pałka J, Wrześniok D, Buszman E, Kaczmarczyk P (2001) Melanin potentiates daunorubicin-induced inhibition of collagen biosynthesis in human skin fibroblasts. Eur J Pharmacol 419:139-145

13. Buszman E, Beberok A, Różańska R, Orzechowska A (2008) Interaction of chlorpromazine, fluphenazine and trifluoperazine with ocular and synthetic melanin in vitro. Pharmazie 63:372-376

14. Yerger VB, Malone RE (2006) Melanin and nicotine: a review of the literature. Nicotine Tob Res 8:487-498

15. Sridharan S, Ganiger K, Satyanarayana A, Rahul A, Shetty S (2011) Effect of environmental tobacco smoke from smoker parents on gingival pigmentation in children and young adults: a cross-sectional study. J Periodontol 82:956-962

16. Hedin CA, Larsson A (1984) The ultrastructure of the gingival epithelium in smokers' melanosis. J Periodontal Res 19:177-190

17. Haresaku S, Hanioka T, Tsutsui A, Watanabe T (2007) Association of lip pigmentation with smoking and gingival melanin pigmentation. Oral Dis 13:71-76

18. Dehn DL, Claffey DJ, Duncan MW, Ruth JA (2001) Nicotine and cotinine adducts of a melanin intermediate demonstrated by matrix-assisted laser desorption/ionization time-of-flight mass spectrometry. Chem Res Toxicol 14:275-279

19. Claffey DJ, Stout PR, Ruth JA (2001) 3H-nicotine, 3H-flunitrazepam, and $3 \mathrm{H}$-cocaine incorporation into melanin: a model for the examination of drug-melanin interactions. J Anal Toxicol 25:607-611

20. Claffey DJ, Stout PR, Ruth JA (2000) A comparison of sodium hydroxide and sodium sulfide digestion of mouse hair in the recovery of radioactivity following systemic administration of $[3 \mathrm{H}]$-nicotine and $[3 \mathrm{H}]$-flunitrazepam. J Anal Toxicol 24:54-58

21. Stout PR, Ruth JA (1999) Deposition of [3H]cocaine, [3H]nicotine, and $[3 \mathrm{H}]$ flunitrazepam in mouse hair melanosomes after systemic administration. Drug Metab Dispos 27:731-735 
22. Szüts T, Olsson S, Lindquist NG, Ullberg S, Pilotti A, Enzell C (1978) Long-term fate of [14C]nicotine in the mouse: retention in the bronchi, melanin-containing tissues and urinary bladder wall. Toxicology 10:207-220

23. King G, Yerger VB, Whembolua GL, Bendel RB, Kittles R, Moolchan ET (2009) Link between facultative melanin and tobacco use among African Americans. Pharmacol Biochem Behav 92:589-596

24. Beberok A, Otręba M, Wrześniok D, Buszman E (2013) Cytotoxic effect of lomefloxacin in culture of human epidermal melanocytes. Pharmacol Rep 65:689-699

25. Wrześniok D, Beberok A, Otręba M, Buszman E (2013) Modulation of melanogenesis and antioxidant defense system in melanocytes by amikacin. Toxicol In Vitro 27:1102-1108

26. Wrześniok D, Otręba M, Beberok A, Buszman E (2013) Impact of kanamycin on melanogenesis and antioxidant enzymes activity in melanocytes - an in vitro study. J Cell Biochem 114:2746-2752

27. Wrześniok D, Beberok A, Otręba M, Buszman E (2013) Netilmicin-induced modulation of melanogenesis in HEMa-LP melanocytes. Acta Pol Pharm Drug Res 70:803-808

28. Wrześniok D, Beberok A, Otręba M, Buszman E (2013) Effect of streptomycin on melanogenesis and antioxidant status in melanocytes. Mol Cell Biochem 383:77-84

29. Ozeki H, Ito S, Wakamatsu K, Thody AJ (1996) Spectrophotometric characterization of eumelanin and pheomelanin in hair. Pigment Cell Res 9:265-270

30. Kim DS, Kim SY, Park SH, Choi YG, Kwon SB, Kim MK, Na JI, Youn SW, Park KC (2005) Inhibitory effects of 4-n-butylresorcinol on tyrosinase activity and melanin synthesis. Biol Pharm Bull 28:2216-2219
31. Busca R, Bertolotto C, Ortonne JP, Ballotti R (1996) Inhibition of the phosphatidylinositol 3-kinase/p70(S6)-kinase pathway induces B16 melanoma cell differentiation. J Biol Chem 271:31824-31830

32. Mars U, Larsson BS (1999) Pheomelanin as a binding site for drugs and chemicals. Pigment Cell Res 12:266-274

33. Delijewski M, Buszman E, Wrześniok D (2013) Nicotine-melanin interaction. Ann Acad Med Siles 67:361-366

34. Lindquist NG, Ullberg S (1974) Autoradiography of intravenously injected 14C-nicotine indicates long-term retention in the respiratory tract. Nature 248:600-601

35. Otręba M, Rok J, Buszman E, Wrześniok D (2012) Regulation of melanogenesis: the role of cAMP and MITF. Adv Clin Exp Med 66:33-40

36. Hedin CA, Larsson A (1986) In vitro activation of amphibian dermal melanocytes by nicotine. Scand J Dent Res 94:57-65

37. Robles GI, Singh-Franco D, Ghin HL (2008) A review of the efficacy of smoking-cessation pharmacotherapies in nonwhite populations. Clin Ther 30:800-812

38. Mari M, Colell A, Morales A, Montfort C, Garcia-Ruiz C, Fernandez-Checa JC (2010) Redox control of liver function in health and disease. Antioxid Redox Signal 12:1295-1331

39. Maresca V, Flori E, Briganti S, Mastrofrancesco A, Fabbri C, Mileo AM, Paggi MG, Picardo M (2008) Correlation between melanogenic and catalase activity in in vitro human melanocytes: a synergic strategy against oxidative stress. Pigment Cell Melanoma Res 21:200-205 